\title{
Changes in Undergraduate AND Graduate Student Perspectives of ONLINE VERSUS FACE-TO-FACE EdUCATION
}

\author{
Lynn A. Fish and Coral R. Snodgrass
}

Lynn A. Fish and Coral R. Snodgrass are Professors of Management, Canisius College, 2001 Main Street, Buffalo, NY

Corresponding Author: fishl@canisius.edu; (716)888-2642

\begin{abstract}
Over 6 years ago at an AACSB Jesuit, Catholic University with a strong focus on teaching, business student perspectives regarding online versus face-to-face courses indicated that students prefer face-to-face classes. However, other researchers have noted changes in student perspectives over time. Other research has noted differences between undergraduate and graduate students with respect to their perceptions. In order to explore these changes and differences, this research explores whether these two populations have changed their perspectives over the past 6 years on individual and program perceptual factors. This research has implications for instructors and administrators.
\end{abstract}


Keywords: Student Perspectives, Undergraduate, Graduate, Online, Face-to-face

DOI: https://dx.doi.org/10.15239/j.brcacadjb.2021.11.01.ja06

\section{LITERATURE REVIEW}

Undoubtedly, online (OL) education in higher education has increased over the past decade, and senior administrators perceive online education to be equivalent to face-to-face (FTF) education (Allen \& Seamen, 2013). Assuming that this is the case then students should be indifferent to all educational factors; however, prior research on student perspectives are mixed, and results at a teaching university clearly demonstrate that students preferred FTF education over OL education for most factors (Fish \& Snodgrass, 2014; 2015).

As technology continues to change and methods to teach and learn in the online environment evolve, research on student perceptions in the online learning environment continues (e.g. Allen \& Seaman, 2013; Perreault, Waldman, Alexander \& Zhao, 2008; Tanner, Noser, and Langford, 2003; Tanner, Noser, Fuselier \& Totaro, 2004a; 2004b; Tanner, Noser, Totaro \& Birch, 2006; Tanner et al., 2009). Learning theory implies that as someone is exposed and uses a particular technology or method, the better and more adept they become. Over a decade ago, research indicated that student with prior OL experience perceived OL courses more favorable than those without prior experience (Tanner et al., 2003). Some research has shown that as the number of OL courses continues to increase, student perceptions of OL education view OL as equal to or better than FTF (Perreault et al., 2008; Mortagy \& Boghikian-Whitby, 2010; Dobbs, Waid, \& del Carmen, 2009). However, at least 5 OL courses are necessary for students to perceive that they learn more in the OL environment than FTF (Dobbs, Waid, \& del Carmen, 2009). A student's self-efficacy, or belief in one's own abilities to perform a given task $\mathrm{OL}$, increases as student's Internet usage frequency increases and is 
related to their prior computer and Internet experiences (Tekinarslan, 2011). Student attitudes and perceptions are important antecedents of the student's inclination toward OL education (Chawla \& Joshi, 2012).

Our literature review is not intended to be a comprehensive review of literature in this area, but rather it serves to clearly indicate the ambiguity that exists in the debate between OL and FTF education. (The interested reader may wish to review our prior research that highlights each of the individual and program factors studied (Fish \& Snodgrass, 2014; 2015; 2019 a, b)). Results are clearly mixed as some indicate that the courses are equally effective across formats (Fowler, 2005; Topper, 2007; Horspool \& Lange, 2012), while others show a preference to FTF over OL environments (Mullen \& Tallent-Runnels 2006), and others show a higher satisfaction for OL learning (Connolly, MacArthur, Stansfield \& McLellan, 2007). As we have noted in our other research articles (Fish \& Snodgrass, 2014, 2015, 2019a, 2019b), these studies differ in the size (small, medium, large universities), audience (e.g. scientific versus social sciences, business versus non-business, and graduate versus undergraduate), and method of research (e.g. interview, survey). Several OL perception studies were completed at large universities or in a public forums (Tanner et al., 2003; Tanner et al., 2004a; 2004b; Tanner et al, 2006; Tanner et al., 2009) or in non-business fields (e.g. Dobbs, Waid, \& delCarmen, 2009; Lanier, 2006; Leasure, Davis \& Theivon, 2000; Reilly et al., 2012; Tekinarslan, 2011; Wang \& Morgan, 2008). Therefore, the context of the study may be an important factor to consider in interpretation of the survey results. Most business student perceptions research was published over 10 years ago (e.g. Perreault et al., 2008; Tanner et al., 2003; Tanner et al., 2004-1, 2004-2), and similar to other studies (Mortagy \& Boghikian-Whitby, 2010; Perreault et al., 2008), perceptions may have changed.

Very little current research exists that explores perceptual differences by the undergraduate and graduate educational levels. Some studies note differences for business versus non-business students (Tanner et al., 2004a; 20004b) and graduate versus undergraduate nursing student 
(Billings, Skiba \& Connors, 2005). For nursing students, results indicated that graduate students spent more time on their courses, needed more instructor attention and found faculty availability to be an issue compared to the undergraduate nursing students (Billings et al., 2005). For criminal justice students, students who have never taken an OL course have different perceptions of OL learning than those who have (Dobbs et al., 2009). A study of undergraduate students' perspective on cheating online revealed that the majority felt it was easier to cheat online compared to the traditional classroom (King et al, 2009), which is similar to the results of our previous study (Fish \& Snodgrass, 2014). Most of these studies are over 10 years old and given technology has changed, student perspectives may have changed as well. A more recent study showed that graduate and undergraduate business students generally perceived OL cheating to be easier and more common than FTF (Larkin \& Mintu-Wimsatt, 2015).

\section{PRESENT STUDY}

Our original research showed that as students acquire more OL experience (based upon those taking more OL courses), their perceptions of OL education became more positive (Fish \& Snodgrass, 2014). These results led us to ask, "With an increase in the number of online courses and technology changes at the University, have the students' other perceptions changed?" Using the same research instrument that we used in 2012, in 2018, we asked the current students at the institution the same questions and noted changes in some factors (Fish \& Snodgrass, 2019 a, b). Those reported results indicate few changes in student responses. While a shift in every individual and program factor did not occur over the six years, there appear to be some changes in perspectives occurring. It should also be noted that there have been a number of changes in the educational environment of the study. The original study occurred in the fall of 2012. Since that time, the number of OL courses has increased at the University. Also, since 2012, instructor methods, technology and software have changed. For example, the University changed to a Desire2Learn 
platform from Angel, from 'GoToMeeting' to Zoom for 'face-to-face' online interaction, and Youtube, Google and other video availability and usage has increased. There has been an increase in the emphasis in transitioning to the online format at the University, with the graduate program especially encouraging the shift. And of course, the students are different. The students who participated in the 2018 research were likely more used to using various forms of information technology such as Instagram. Consequently, their level of comfort with technologically mediated communication would be expected to be higher than of those 2012 students,

As part of a much large study that directly compared the online versus the FTF environment (Fish \& Snodgrass, 2019 a, b), our intent within this paper is to explore changes in undergraduate and graduate student perceptions of FTF versus OL education with respect to both individual and program factors.Therefore, for all of the individual and program factors studied, this leads to our Research Questions (Hypotheses are listed in appendix A of web appendix):

\#1) Do undergraduate and graduate business students in 2012 and 2018 perceive the OL and FTF learning environments equally for all individual and program factors?

\#2) Have undergraduate and graduate business students' perspectives on OL and FTF learning environments changed over the past 6 years?

\#3) Do undergraduate students who have and have not experienced $O L$ education, perceive the OL and FTF environments equally for all individual and program factors?

\#4) Do graduate students who have and have not experienced $O L$ education, perceive the $O L$ and FTF environments equally for all individual and program factors?

Our study was conducted at a mid-sized, Jesuit, Catholic, business school with a focus on teaching. The research focus lies in uncovering student perceptions where FTF class sizes average 17 students with a capacity of 
35 students. Online education is a growing educational method; however, not all students at the University have experienced this medium (Allen \& Seaman, 2013). Based upon the literature, the intent of this research is to explore current undergraduate and graduate students' perceptions of online education for those who have experienced it and those who have never experienced online and compare it to the perceptions from over 6 years ago. Theoretically, students should perceive the environments equally and not favor either traditional FTF or online education.

\section{METHOD}

The focus population of our study is an AACSB-accredited, Jesuit, Catholic University in the northeast, specifically undergraduate and graduate business students. Students voluntarily completed an online Qualtricsadministered survey during the month of November 2018. The survey link was sent to business students via a list serve twice over the month. 74 undergraduate students and 60 graduate students participated in the 2018 survey. A similar survey was administered directly in class to students in FTF classes in fall of 2012, and 63 undergraduate and 47 graduates participated (Fish \& Snodgrass, 2014). However, since students were not required to answer every question, the data set reflected fewer responses for some factors.

The survey was designed to test student perceptions of difficulty, motivation, student-to-student interaction, student-to-instructor interaction, discipline, cheating, self-directed, independence, schedule flexibility, time investment, cost investment, preference for online or FTF environments, happiness with online or FTF education, and appropriateness of online at the University (See Appendix). Students were also questioned as to which activities increased or decreased the understanding of course material. The selection of activities included discussion boards, in-class sessions, reading, homework, videos, instructor lectures, instructor chat, other students, problem scaffolding \& hints, or 'other'. In the original 2012 study, background information gathered included class level, gender and 
online experience. In the 2018 study, background information included class level (undergraduate - freshmen, sophomore, junior, senior or graduate), age, gender, major (undergraduate) or concentration (graduate), self-described level of technological understanding, and whether the student was a transfer student.

Students who experienced at least 1 online course completed Section A ("Online"), while students who had never taken an online course completed Section B ("Traditional FTF"). Sections A and B had corresponding questions, but Section A statements were specific to "I found" versus Section B statements were "I perceive". The last questions in each section asked the student if they would prefer the opposite environment, their emotional happiness with the learning environment, and whether online courses were appropriate for the institution. For students with online experience, the last question inquired why they chose to take an online course. For students without online experience, the survey included an open-ended question inquiring 'why not'. Information from the surveys was codified as Significantly Less (1), Less (2), The Same (3), More (4) and Significantly More (5), and the data was entered into SPSS for analysis.

\section{ANALYSIS}

For purposes of our study, as shown in Table 1, 44 students split equally between undergraduate and graduate students completed the $2012 \mathrm{OL}$ portion of the survey, while 41 undergraduates and 25 graduate students completed the 2012 FTF portion of the survey. In the 2018 survey, 82 students -40 undergraduate and 42 graduates - completed the OL portion of the survey. In 2018, 52 students - 34 undergraduates and 18 graduates - completed the FTF portion of the survey.

Given the survey setup, responses positively viewed the environment that a student was part of. For example, if an online student felt that online was more difficult than FTF, he or she would indicate a significant 


\section{The BRC Academy Journal of Business Vol. 11, No. 1}

'positive' for the online environment. The scale for the FTF students was similar for their environment. Therefore, if the two groups perceive the learning environment differently than their own environment, a significant difference between the two groups would be detected. As noted in prior research articles (Fish \& Snodgrass, 2014, 2015, 2019 a, b), the reader should note that in 2012 every individual factor and program factor - except appropriateness of OL and a slight significance for discipline and time investment - a significant difference existed between the OL and FTF groups. By 2018, significant differences existed on most factors except for discipline, self-directed and happiness. Significant changes in OL student perspectives existed for self-directed, time investment and appropriateness, and for FTF students significant changes in perspectives existed for self-directed, student-to-instructor interaction, preference, happiness and appropriateness (Fish \& Snodgrass, 2019 a, b). Essentially both groups had similar perspectives on which environment they favored, as in general, they favored FTF over OL but indicated that cheating was easier OL and schedule flexibility were preferred OL.

Since we cannot statistically test the simultaneous significance to being an undergraduate versus a graduate and OL versus FTF, the analysis must consider each perspective - OL versus FTF separately. Given the students - either undergraduate or graduate - are part of the same environment of the survey, their perspectives should be the same in this analysis and significant differences would demonstrate differences between undergraduates and graduates.

In the prior study, the responses for each of the individual and program factors for the OL undergraduates and graduates are shown in Table 2 (Fish \& Snodgrass, 2014, 2015). With respect to the 2012 results, as shown in Table 3, undergraduate and graduate OL students were indifferent in their perceptions of all factors except for a slight significance for interaction between students $(\mathrm{p}=.088)$ and appropriateness of $\mathrm{OL}(\mathrm{p}=.063)$. Undergraduate students are more indifferent to the two environments on student-to-student interaction than their graduate counterparts, who 
favored the FTF environment over the OL environment on this factor. Interestingly, while appropriateness of OL education was indifferent overall, OL undergraduate and graduate students differed slightly on this factor. Significantly more 2012 graduate students felt that OL education is not appropriate versus their undergraduate counterparts.

Responses on each factor for the undergraduate and graduate students who completed the FTF portion of the 2012 survey are shown in Table 4 (Fish \& Snodgrass, 2014 2015). As shown in Table 5, FTF undergraduate and graduate perspectives on every factor are similar as no significant differences were noted.

Undergraduate and graduate student responses for the 2018 OL perspective are shown in Table 6. As shown in Table 7, the only significant differences between undergraduate and graduate perspective are for student-to-student interaction and a slight significance for happiness. In general, undergraduate students are more indifferent to studentto-student interaction between the two environments, while graduate students favor FTF interaction on this factor. As for happiness with the OL environment, undergraduate students are slightly more favorable in their perspective of the OL environment than graduate OL students.

The 2018 undergraduate and graduate responses for students who had never taken an OL course are shown in Table 8. Similar to the 2012 results, there is no significant difference between the perspectives of the undergraduate and graduate students on any factor except for happiness, as shown in Table 9. Undergraduate FTF students are happier in the FTF environment, while graduate students are more indifferent.

We continue by analyzing the undergraduates and graduates for each of the survey years, and analyze differences across the years for undergraduates and graduates.

Undergraduate Students. Given the overall results and as shown in Table 10, 2012 OL and FTF undergraduate students significantly differed on most factors. For the factors, since we are comparing opposite 
environments, significance indicates a preference towards a similar perspective. In general, students tend to prefer the FTF environment for motivation, prefer student-to-student interaction, student-to-instructor interaction, discipline, preference for opposite, and happiness. Students perceived cheating to be easier OL, preferred the schedule flexibility and cost investment for OL. Discipline and appropriateness are slightly significant. Interestingly, difficulty, independence, and time investment are insignificant. In other words, students preferred the same environment regardless of their survey perspective.

Interestingly, as shown in Table 11 by 2018 , undergraduate OL and FTF students significantly differed on each of the factors that the 2012 cohort was indifferent to, that is, difficulty, independence and happiness with the environment. By 2018, undergraduate students significantly differed on these factors that were not significantly different in 2012. By 2018, OL and FTF students significantly differed on most factors and particular, undergraduate students preferred the same perspective on every factor except for discipline, self-directed and happiness. (All three factors were significantly different between OL and FTF undergraduate students in 2012). Responses demonstrated a preference towards FTF on difficulty, motivation, student-to-student interaction, student-toinstructor interaction, more difficult to cheat FTF, independence, time investment, cost investment, and preference for the opposite environment. Both groups preferred OL for schedule flexibility, and OL students overwhelmingly approved of the appropriateness of OL versus their FTF counterparts.

As shown in Table 12, a comparison of differences in undergraduate perspectives for students who had taken at least 1 OL course found that undergraduate student perspectives had not changed over the 6 years on almost all factors except for time investment and a slight significance for student-to-instructor interaction. While the 2012, OL undergraduate student responses varied on time investment, most 2018 OL undergraduates were indifferent to the two environments. By 2018, 
undergraduate OL students tended to prefer FTF student-to-instructor interaction more than the 2012 respondents, who were more indifferent on this factor.

As for a comparison for undergraduate students who have never taken an OL course, as shown in Table 13, significant differences in perspectives exist for preference for the opposite environment and happiness in the FTF environment, and slightly significance for studentto-instructor interaction and self-directed. In general, FTF undergraduate students in 2012 did not want to attempt an OL course, but by 2018, FTF undergraduate students had a preference towards attempting an OL course. Similarly, in 2012, FTF undergraduate students appeared to be very happy in the FTF environment, but by 2018, they were more indifferent to the two environments.

Graduate Students. With respect to an in-depth analysis for graduate students, in 2012, several factors as shown in Table 14 were significantly different between OL and FTF student perspectives. Graduate students favored the FTF environment for motivation, student-to-student interaction, student-to-instructor interaction, and preference for the opposite environment. As for cheating, both groups felt it was more difficult to cheat FTF than OL, and both tended to prefer OL more than FTF for schedule flexibility. With respect to independence, FTF tended to see the environments equally, while OL students preferred OL. FTF graduate students felt that FTF cost more than OL and were happy with the FTF environment, while OL students were indifferent. Graduate students were essentially indifferent on difficulty, discipline, and time investment. Both groups indicated that OL education was appropriate.

With respect to graduate FTF students, as shown in Table 15, not all factors were significantly different between the two environments. Graduate students significantly differed on motivation, interaction between students, student-to-instructor interaction, cheating, schedule flexibility, and cost investment. Graduate students favored the FTF environment for motivation, student-to-student interaction, and student-to-instructor 
interaction. As for cheating, OL and FTF graduate students felt it was easier to cheat OL and felt OL offered more schedule flexibility than FTF. In general, graduate students were indifferent to the cost investment or perceived online education to cost less than FTF education. By 2018, OL and FTF students shared similar perceptions on a number of factors including difficulty, discipline, self-directed, independence, time investment, preference for the opposite environment, happiness with the environment, and appropriateness.

Interestingly, OL and FTF graduate students in 2018 did not significantly differ on their perceptions for several factors: difficulty, discipline, selfdirected, independence, or time investment. Both groups were relatively indifferent to difficulty and discipline, but they tended to prefer their own environment for self-directed, independence and time investment. Additionally, OL and FTF graduate students did not significantly differ on their preference for the opposite as FTF students were evenly divided into each of the categories, essentially indicating their indifference, while OL graduate students were split between wishing to be in a FTF class and indifference. By 2018, OL graduate students were happy with the OL environment or were indifferent, while their FTF counterparts tended to be happier in the FTF classroom. Roughly $75 \%$ of graduate students perceive OL education to be appropriate at the University.

As shown in Table 16, for every factor except appropriateness of OL education, there was no significant difference between the OL graduate students' perspectives in 2012 and 2018. In 2012, both groups indicated that $\mathrm{OL}$ was appropriate, but there were many in the group that were indifferent or did not support OL education. By 2018, graduate OL students in both groups overwhelmingly supported OL as being appropriate. Similar results as shown in Table 17 exist for the FTF graduate comparison where a significant difference did not exist on every factor except for a slight significance on student-to-instructor interaction. The 2012 FTF graduates overwhelmingly preferred the interaction in the FTF classroom, 
while the 2018 FTF graduates were not as favorable to the interaction in the FTF classroom.

\section{DISCUSSION}

While technology in education continues to advance, students' perspectives on OL versus FTF education at a Jesuit, Catholic AACSB-accredited University have not significantly changed over six years (Fish \& Snodgrass, $2019 \mathrm{a}, \mathrm{b})$. In this portion of a larger project, we analyzed the differences between undergraduate and graduate students' perspectives. Essentially these results demonstrate that for a particular survey year, there are very few differences between undergraduate and graduate business students' perspectives on the various individual and program factors associated with this study. Therefore, in general, our results support and as undergraduate and graduate students' perceptions of OL education for the individual and program factors are similar regardless of whether they have experienced an OL course or they have not. This is in contrast to the significant differences between graduate and undergraduate nursing students' perspectives of OL and FTF noted over a decade ago (Billings, Skiba \& Connors, 2005). However, the population studied here were business students and not nursing students. Perhaps the audience and their major is a significant difference as we have proposed in our other research articles (Fish \& Snodgrass, 2014, 2015, 2019a, 2019b),

Additionally, the perspective for undergraduates and graduates did not change over the six years, in support of and for most individual and program factors. In general, undergraduate and graduate students tend to prefer the FTF environment for difficulty, motivation, student-toinstructor interaction, discipline, self-directed, preference for opposite, and happiness. As for student-to-instructor differences, these results contrast to a prior study that found graduate and undergraduate students differed in their perspectives on student-to-instructor interaction (Billings et al., 2005). Undergraduate and graduate students preferred the schedule flexibility OL, and felt time and cost investment is less OL. Both OL and 
FTF students showed a preference to their survey-designated environment for independence. OL students overwhelmingly indicated that OL education is appropriate, while FTF students who had never experienced OL themselves did not as strongly support it as being appropriate. Interestingly, student-to-student interaction was slightly significant between OL undergraduate and graduate perspectives in 2012, and by 2018 , there was a significant difference on this factor. By 2018, undergraduate students were indifferent to the environments for student-to-student interaction, but graduate students preferred the FTF environment for this factor. For both study years, undergraduate and graduate students' perceived cheating to be easier OL, which supports the prior results where undergraduate and graduate students felt it was easier to cheat online than FTF (Larkin \& Mintu-Wimsatt, 2015).

With respect to undergraduate students, OL and FTF students favored the same perspectives on OL and FTF education for both study years, and OL and FTF undergraduate students did not change over the six years, supporting and, for most factors When comparing the $2012 \mathrm{OL}$ undergraduates to the $2018 \mathrm{OL}$ undergraduates, the preferences were the same except for time investment and a slight significance for studentto-instructor interaction. While 2012 respondents were indifferent on student-to-instructor interaction, by 2018 OL undergraduate students tended to prefer the FTF environment. Interestingly, while only slightly significant, a shift for the FTF undergraduate student appeared for studentto-instructor interaction also, but the FTF students appear to be shifting from overwhelmingly preferring FTF student-to-instructor interaction in 2012 to being 'slightly more' satisfied with FTF education on this factor by 2018 . With respect to the 2012 and 2018 FTF responses, results were similar for most factors. Significant differences in perspectives exist for FTF undergraduate perspectives on preference for the opposite environment and happiness. In 2012, FTF students strongly preferred the FTF environment; however, by 2018, they were more indifferent to the environments. In 2012, FTF undergraduate students appeared to be very 
happy in the FTF environment, but by 2018, they were more indifferent to the two environments.

Similar to the undergraduate students, OL and FTF graduate students favor the same perspectives on OL and FTF education for both study years, and OL and FTF graduate students' perspectives did not change over the six years, supporting and for most factors. However, while a significant shift in perspective for most individual and program factors was not demonstrated for the graduate OL or graduate FTF students over the six years, interestingly as shown in Tables 14 and 15, a few factors that were significant in 2012 were not significant in 2018. Independence, self-directed, preference for the opposite and happiness changed from a significant difference in perspectives in 2012 to an insignificant difference by 2018. Comparing the OL groups in the survey, the only shift in perspectives is for appropriateness of OL education. By 2018, graduate students overwhelming support OL education as being appropriate. While the graduate FTF groups did not differ significantly in their perspectives on any factor, interestingly, there is a slight significance for student-toinstructor interaction. This result has implications for faculty teaching in the FTF classroom as graduate students appear to be shifting their perspective on this critical aspect of the educational environment. In general, while graduate students still tend to prefer FTF education for most factors, they appear to be becoming more amenable to OL education.

\section{CONCLUSIONS}

In spite of changes in technology and educational delivery options, our results show very few differences in perspectives on OL versus FTF education between undergraduate and graduate business students, and this result was consistent and did not change between the 2012 and 2018 survey groups. Undergraduate and graduate students perceive that it is easier to cheat online, which is in keeping with other studies. While the undergraduate results showed very few changes in their perspectives on individual and program factors and both undergraduates and graduate 
students still prefer FTF education for most factors, graduate students appear to be becoming more indifferent to the two environments. As we've noted here and in our prior studies, the context of the study may be a critical factor to consider in understanding student preferences as a prior study found significant differences between undergraduate and graduate nursing students. Perhaps over time, statistically significant differences between these two populations will exist.

\section{REFERENCES}

Allen, I., \& Seaman, J. (2013). Changing Course: Ten Years of Tracking Online Education in the United States. The Sloan Consortium (SloanC), Retrieved on January 11, 2013 from http://sloanconsortium.org/ publications/survey/making_the_grade_2006

Armstrong, D.A. (2011). Students' Perceptions of Online Learning and Instructional Tools: A Qualitative Study of Undergraduate Students Use of Online Tools. The Turkish Online fournal of Educational Technology - July 2011, 10(3), 222-226.

Billings, D.M., Skiba, D.J. \& Connors, H.R. (2005). Best Practices in Webbased Courses: Generational Differences Across Undergraduate and Graduate Nursing Students. Journal of Professional Nursing, 21(2), 126-133.

Chawla, D. and Joshi, H. (2012). E-learning perception and its relationship with demographic variables: a factor analysis approach. International fournal of Information and Communication Technology Education, 8(4), 105-118.

Connolly, T.M., MacArthur, E., Stansfield, M. \& McLellan, E. (2007). A quasi-experimental study of three online learning courses in computing. Computers \& Education, 49, 345-59.

Dobbs, R., Waid, C.A., \& del Carmen, A. (2009). Students' Perceptions of Online Courses: The Effect of Online Course Experience. Quarterly Review of Distance Education, Spring 2009, 10(1), 9-26.

Fish, Lynn A. and Snodgrass, Coral R. (2019 a). A Preliminary Study of Changing Business Student Perceptions of Program Factors in 
Online versus Face-to-Face Education. Northeast Decision Sciences Institute 2019, Philadelphia, PA, April 4-6, 2019. https://nedsi.net/ past-proceedings

Fish, Lynn A. and Snodgrass, Coral R. (2019 b). A Preliminary Study of Changing Business Student Perceptions of Individual Factors in Online versus Face-to-Face Education. WNY Business Research Consortium, March 30, 2019, Niagara Falls, NY.

Fish, L.A. and Snodgrass, C. R.. (2015). Student Perceptions of Online versus Face-to-Face Education: Student Characteristics. Business Education Innovation fournal, 7(2), 83-94.

Fish, L.A. and Snodgrass, C. R. (2014). A Preliminary Study of Business Student Perceptions of Online versus Face-to-Face Education. BRC fournal of Advances in Education, pp. 1-21. DOI: http://dx.doi.org/1 0.15239/j.brcacadje.2014.04.01.ja01

Fowler, D. (2005). Are on-site courses as effective as online? Online Cl@ssroom: Ideas for Effective Online Instruction, March, 1-2.

Horspool, A. \& Lange, C. (2012). Applying the scholarship of teaching and learning: student perceptions, behaviors and success online and face-to-face, Assessment \& Evaluation in Higher Education, February 2012, 37(1), 73-88, Accessed on January 8, 2013 from http://dx.doi. org/10.1080/02602938.2010.496532.

King, C, Guyette, R. and Piotrowski, C. (2009). Online exams and cheating: An empirical analysis of business students' views. The fournal of Educators Online, 6(1), 1-11.

Lanier, M. (2006). Academic Integrity and Distance Learning. Fournal of Criminal Fustice Education, Sep 2006, 17(2), 244-21.

Larkin, C. and Mintu-Wimsatt, A. (2015). Comparing Cheating Behaviors among Graduate and Undergraduate Online Business Students. fournal of Higher Education Theory and Practice, 15(7), 54- 62.

Leasure, A. R., Davis, L., \& Thievon, S. L. (2000). Comparison of student outcomes and preferences in a traditional vs. World Wide Web-based baccalaureate nursing research course. fournal of Nursing Education, 39(4), 149-154. 
Mortagy, Y. \& Boghikian-Whitby, S. (2010). A Longitudinal Comparative Study of Student Perceptions in Online Education. Interdisciplinary Journal of E-Learning and Learning Objects, 6, 23-46.

Mullen, G.E., \& Tallent-Runnels, M.K. (2006). Student outcomes and perceptions of instructors' demands and support in online and traditional classrooms. Internet and Higher Education, 9, 257-66.

Perreault, H., Waldman, L., Alexander, M. \& Zhao, J. (2008). Graduate Business Students' Perceptions of Online Learning: A Five Year Comparison. The Delta Pi Epsilon fournal, Fall 2008, L(3), 164-179.

Reilly, J.R., Gallager-Lepak, S. \& Killion, C. (2012). Me and My Computer: Emotional Factors in Online Learning, Nursing Education Perspectives, March/April, 33(2), 100 - 105.

Tanner, J., Noser, T., \& Langford, H. (2003). Perceptions of Undergraduate Business Students Toward Online Courses In Higher Education Expanded and Revisited: Do Gender, Age, and/or Past Experiences Make a Difference? Journal of Business and Economics Research, 1(2), 13-20.

Tanner, J., Noser, T., Fuselier, J., \& Totaro, M. (2004a). 'The Online 'Classroom': Differences in Perception between Business Students and Non-Business Students. Journal of College Teaching and Learning, 1(3), 37-44.

Tanner, J., Noser, T., Fuselier, J., \& Totaro, M. (2004b). 'The Online 'Classroom': What Do Students Think? Journal of Informatics Education Research, 6 (1), 43-54.

Tanner, J., Noser, T., Totaro, M., \& Birch, R. (2006). Student Perceptions of The Online 'Classroom': An Update. International Business \& Economics Research fournal, 5(10), 31-38.

Tanner, J.R., Noser, T.C., \& Totaro, M.W. (2009). Business Faculty and Undergraduate Students' Perceptions of Online Learning: A Comparative Study. Journal of Information Systems Education, Spring 2009, 20(1), 29-40.

Tekinarslan, E. (2011). Faculty of Education Students' Self-efficacy Perceptions toward Online Technologies. Electronic fournal of Social Sciences, Summer 2011, 10(37), 120-134. 
Topper, A. (2007). Are they the same? Comparing the instructional quality of online and face-to-face graduate education courses. Assessment \& Evaluation in Higher Education, 32 (6), 681-691.

Wang, L.C. \& Morgan, W.R. (2008). Student Perceptions of Using Instant Messaging Software to Facilitate Synchronous Online Class Interaction in a Graduate Teacher Education Course. fournal of Computing in Teacher Education, Fall 2008, 25(1), 15-21.

\section{Citation Information}

Fish, Lynn A., and Coral R. Snodgrass. "Changes in Undergraduate and Graduate Student Perspectives of Online versus Face-to-Face Education.” The BRC Academy fournal of Business 11, no. 1 (2021): 147-165. https:// dx.doi.org/10.15239/j.brcacadjb.2020.11.01.ja06

\section{Web Appendix}

A web appendix for this paper is available at: https://dx.doi.org/10.15239/ j.brcacadjb.2021.11.01.wa06 